\title{
The Most Important Methods for Reducing Chemotherapy-Induced Nausea and Vomiting In Cancer Patients: A Systematic Review Study
}

\section{MOSTAFA MADMOLI*1 ${ }^{*}$ MAHTAB SAMSAMIPOUR²}

INTRODUCTION: Despite the successes that have recently been made in the field of control and prevention of communicable diseases, the incidence of chronic illnesses has increased. And cancer as a chronic disease after accidents and unintentional deaths is the third leading cause of death in children. Given that cancer patients have multiple chemotherapy during their healing period and chemotherapy itself causes a lot of harm to the patient and that nausea and vomiting are a common complication in chemotherapy patients, Therefore, this systematic review was conducted to determine the most important methods for reducing the nausea and vomiting induced by chemotherapy in cancer patients. MATERIALS AND METHODS: This study is a systematic review Using the articles published in the last 20 years, it was based on the most important methods for reducing the nausea and vomiting of chemotherapy in cancer patients. The search was carried out in search engines, SID, Magiran, and Google Scholar, Embase, ResearchGate, Sciencedirect, and PubMed in Persian and English. In the first stage, 47 articles were found. Of these, 10 related articles that have been published in the last 20 years have been reviewed.

RESULTS: In this study, we investigated the most important methods for reducing the nausea and vomiting of chemotherapy in cancer patients. In one of these studies, the rate of nausea and vomiting in patients undergoing chemotherapy was studied at the stage. In the first stage, without intervention, in the second phase, music was broadcast to patients using headphones. In the case of nausea, measurements with numerical criteria at 16 and 24 hours and descriptive criteria showed significant difference only at 24 hours after chemotherapy. However, there was no significant difference in vomiting between two stages of chemotherapy.

CONCLUSION: According to the studied studies, ice massage in the Negan spot can be effective in reducing the frequency and severity of nausea and vomiting in cancer patients undergoing chemotherapy. It can also be said that muscle use reduces nausea in children with chemotherapy malignancy. It is suggested that nurses use ear acupressure technique as a complement to relieve nausea and vomiting caused by chemotherapy.

KEYWORDS: Chemotherapy, Cancer, Nausea, Vomiting, Quality of Life

\section{INTRODUCTION}

Nausea is the most common and disturbing complication of chemotherapy in cancer patients, which has criticized the success of this method to a large extent. ${ }^{1}$ Nausea caused by chemotherapy causes many problems for patients and sometimes these problems are severe so that they can stop them from continuing treatment. ${ }^{2}$ Because it has many negative effects on the quality of life and their daily functioning. ${ }^{3}$ Research shows that 20 to 30 percent of patients are predicted from nausea and most of them also suffer from acute nausea. ${ }^{4}$

Among cancer patients, diabetes is one of the most important causes of the disease. Diabetes is a chronic and metabolic disease and is a major cause of morbidity and mortality in the industrialized world. And due to its late and dangerous effects, it has been paying more attention on a daily basis and the World Health Organization has called it an "epidemic". 5-19 Diabetes complications can lead to increased mortality in people with diabetes, which causes high costs for individuals and society. Today, diabetes is one of the most important health and socio-economic problems in the world. ${ }^{20-33}$ Complications of diabetes

are very common among patients. ${ }^{5}$ Among diabetic patients, depression is one of the most common psychiatric disorders. ${ }^{34}$ Depression is common in today's societies, especially among young people and adolescents. ${ }^{35,36}$ Depression and occupational stress daily may cause disorders in people's health. ${ }^{37}$ Diabetes is also the most common endocrine disorder among patients with thalassemia. ${ }^{38}$ Thalassemia is one of the diseases and problems of today's societies that afflicts people with quality of life. In general, diabetes can be caused by several complications. ${ }^{39-44}$

Overall, it can be said that increased type 2 diabetes is associated with an increased risk of certain specific cancers. ${ }^{45}$ Given that cancer patients undergo chemotherapy, their quality of life is severely affected, and nausea and vomiting are the most unpleasant 
and most terrible complications of chemotherapy. Therefore, this systematic review was conducted to determine the most important methods for reducing the nausea and vomiting induced by chemotherapy in cancer patients.

\section{MATERIALS AND METHODS}

This study is a systematic review using the articles published in the last 20 years, it was based on the most important methods for reducing the nausea and vomiting of chemotherapy in cancer patients. The search was carried out in search engines, SID, Magiran, and Google Scholar, Embase, ResearchGate, Sciencedirect, and PubMed in Persian and English. In the first stage, 47 articles were found. Of these, 10 related articles that have been published in the last 20 years have been reviewed.

This systematic review was conducted based on the Broome method. The purpose of this method was to achieve the purpose of the study and to enhance the study's thorough understanding and comprehension. The method is based on three steps in the search of texts, data evaluation and data analysis. In the search for texts, post-retrospective studies are examined in four stages in terms of inclusion criteria and after obtaining the terms of entry into the study, the content of the study is evaluated, and at the end of the analysis of the data.

To achieve relevant studies, a wide range of keywords including chemotherapy, cancer, nausea, vomiting and quality of life was used as a one-to-one search, combined with the method "And" and "OR".

The studies studied were written in English or Persian, access to their full text was possible and published in the last 20 years, were included in the study and unnamed studies were deleted without history and non-academic.

\section{RESULTS}

Nausea is the most common and disturbing complication of chemotherapy in cancer patients, which has criticized the success of this method to a large extent. ${ }^{1}$ Nausea caused by chemotherapy causes many problems for patients and sometimes these problems are severe so that they can stop them from continuing treatment. ${ }^{2}$ Because it has many negative effects on the quality of life and their daily functioning. ${ }^{3}$ Research shows that 20 to 30 percent of patients are predicted from nausea and most of them also suffer from acute nausea. ${ }^{4}$

Given that cancer patients undergo chemotherapy, their quality of life is severely affected, and nausea and vomiting are the most unpleasant and most terrible complications of chemotherapy. Therefore, this systematic review was conducted to determine the most important methods for reducing the nausea and vomiting induced by chemotherapy in cancer patients.

In a study in two groups, the severity of nausea in the group of cardamom was significantly lower than the placebo at the end of the interventions, which was statistically significant. The number of nausea and vomiting in the acute phase was similar in both groups at the beginning of the study. ${ }^{46}$

In another study, 2 hours after chemotherapy, the nausea score of the two groups increased. The increase in the control group was significantly higher than the intervention group. At the second hour of chemotherapy, the nausea score of both groups was lower in garlic but at all times, the nausea score in the control group was significantly higher than the intervention group. ${ }^{47}$

The results of one study showed that the mean nausea scores in the control group increased on the first day and decreased in the intervention group. But in the first, second, third and fourth days, there was no significant difference between the two groups. ${ }^{4}$

In a study in the intervention group, ginger capsules were taken orally, four times a day, at intervals of six hours. The findings of this study showed that the number of vomiting cases in the acute phase was significantly lower in the ginger group than in the placebo group. Also, the use of ginger capsules did not cause a specific complication compared with placebo. 49

In another study, the first stage was broadcast without intervention, and in the second phase, music was distributed to patients using headphones. In the case of nausea, measurements with numerical criteria at 16 and 24 hours and descriptive criteria showed significant difference only at 24 hours after chemotherapy between the two stages..$^{\circ}$ In a study in the intervention group, ginger capsules 
were taken every 12 hours every other day, one hour before chemotherapy, until five days later and the control group received only a routine diet. At the end of the intervention, the findings indicated that ginger was effective in reducing the number of cases of nausea and vomiting. ${ }^{51}$

In another study in the experimental group, massage of the Negan point of the wrists caused a significant reduction in the frequency of nausea and vomiting, as well as a reduction in the severity of nausea and vomiting. Compared with the control group, the mean number of nausea in the treatment group was significantly decreased..$^{2}$

In another study that investigated the effect of massage therapy on vomiting in patients undergoing chemotherapy for breast cancer, there was no significant difference between the intervention and the control group. Therefore, massage reduces vomiting, but this is not significant..$^{53}$

In one study, the results showed that the use of acupressure in the ear caused a reduction in severity and frequency of nausea in the acute phase, which was statistically significant. ${ }^{54}$

Other study results showed that the use of mint extract containing ice cream was effective on chemotherapy-induced nausea but was not effective in chemotherapy-induced vomiting. 55

\section{DISCUSSION}

As stated, nausea is the most common and debilitating complication of chemotherapy in cancer patients, which criticized the success of this method to a large extent. ${ }^{1}$ Nausea and vomiting are the most unpleasant and most terrible complications of chemotherapy. Therefore, this systematic review was conducted to determine the most important methods for reducing the nausea and vomiting induced by chemotherapy in cancer patients.

According to study ${ }^{46}$, it can be said that Inhalation aromatherapy essential oil of cardamom is recommended to reduce the severity of chemotherapy-induced nausea in cancer patients. The cardamom is from the family of ginger that is known as queen of spices. One of its uses is to relieve nausea and vomiting. According to study ${ }^{47}$, the results showed that the use of chamomile extract reduces nausea induced by chemotherapy, but is not effective in reducing vomiting. From herbs, the chamomile has anti-inflammatory properties and vomit. ${ }^{56,57}$ Which in this study reduced the number of nausea induced by chemotherapy. Also, daily consumption of $1 \mathrm{~g}$ of ginger powder in capsule form may help to reduce acute vomiting from the three days prior to chemotherapy up to three days later and in combination with antiviral and standard vomiting regimens..$^{49}$ Also, according to study ${ }^{50}$, it can be said that using music reduces nausea in children with malignancy under chemotherapy. Also ${ }^{51}$, it can be said that the results of the study show that taking one gram of Ginger in the first five days of chemotherapy reduces the number of nausea cases and the number of vomiting cases in the acute phase. Also, Shermeh MS et al..$^{2}$ showed that ice massage in the Negan spot is effective in reducing the frequency and severity of nausea and vomiting in cancer patients undergoing chemotherapy. In another study, the use of acupressure in the gravel, heart, stomach, central nervous system, and the source of the nose, along with the anti-nausea and vomiting regimen, could lead to relief of nausea and vomiting of the acute phase. ${ }^{54}$

\section{CONCLUSION}

According to the studied studies, ice massage in the Negan spot can be effective in reducing the frequency and severity of nausea and vomiting in cancer patients undergoing chemotherapy. It can also be said that muscle use reduces nausea in children with chemotherapy malignancy. It is suggested that nurses use ear acupressure technique as a complement to relieve nausea and vomiting caused by chemotherapy.

\section{ACKNOWLEDGMENT}

The author of this article is grateful to all those who have collaborated with me in this article.

\section{REFERENCES}

1. Boakes RA, Tarrier N, Barnes W, Tattersall MH. Prevalence of anticipatory nausea and other sideeffects in cancer patients receiving chemotherapy. Eur J Cancer 1993;29A (6):866-70.

2. Grunberg SM, Deuson RR, Mavros P, Geling O, Hansen $M$, Cruciani $G$, et al. Incidence of chemotherapy-induced nausea and emesis after modern antiemetics. Cancer 2004;100(10):2261-8.

3. Hickok JT, Roscoe JA, Morrow GR, Ryan JL. A Phase II/III Randomized, Placebo-Controlled, Double-Blind Clinical Trial of Ginger (Zingiber officinale) for Nausea Caused by Chemotherapy for 
Cancer: A Currently Accruing URCC CCOP Cancer Control Study. Support Cancer Ther 2007;4(4):247-50. 4. Moslemirad M, Madmoli M, Madmoli Y, Niksefat M. Prevalence of type 1 and type 2 diabetes and its related factors in diabetic patients hospitalized in Khatam-ol-Anbia hospital in Shoushtar, 2014-15: A retrospective study. Journal of Research in Medical and Dental Science. 2018;6(3):421-6.

5. Madmoli M, Eilami O, Rezaie K, Aliabad MA, Moslemirad M. Diabetes and the risk of suffering cardiovascular Diseases: A two-year retrospective study. International Journal of Ecosystems and Ecology Science (IJEES). 2018;8(3):649-56.

6. Madmoli M Rostami F, Mirsami Yazdi N, Mosavi A, Baraz Sh. Evaluation of Prevalence of Diabetic Foot Ulcer and Its Related Factors in Diabetic Patients Admitted to KHatam-ol-Anbia Hospital in Shoushtar During 2015-2016: A Retrospective Study. International Journal of Ecosystems and Ecology Science (IJEES). 2018;8(3): 545-52.

7. Rostami F, Madmoli M, Mirsami Yazdi N, Baraz Sh. Evaluation of The Prevalence of Lower Limb Amputation and Its Related Factors in Diabetic Patients Admitted to KHatam-ol-Anbia Hospital in Shoushtar During The 2015-2016: A Retrospective Study. International Journal of Ecosystems and Ecology Science (IJEES). 2018;8(3):553-60.

8. Raisifar Z, Afshar Nia A, Madmoli M, Madmoli Y. The Relationship Between Using Insulin and Suffering Alzheimer's Disease in Patients with Diabetes: A Two-Year Study. International Journal of Ecosystems and Ecology Science (IJEES). 2018;8(3): 623-28.

9. Raisifar Z, Afshar Nia A, Maghamesi Moarrefi H, Madmoli M. Evaluation of Gi Bleeding Prevalence and Its Related Factors in Diabetic Patients Hospitalized in KHatam-ol-Anbia Hospital During 2015-16: A Retrospective Study. International Journal of Ecosystems and Ecology Science (IJEES). 2018;8(3):609-14.

10. Madmoli M, Kord Z, Bandani A, Sedighi N, Rezaei Shandiz M, Darabiyan P, AfsharNia A. Epidemiological and clinical study of patients with Alzheimer's in Five Cities of Khuzestan Province in 2016-2018. Medical Science, 2019; 23(95):1-5.

11. Mashali H, Toleideh F, Rahmani R, Darabiyan P, Madmoli M. The predictive role of Hyperlipidemia in the incidence of ACS in patients referring to Shahidzadeh Hospital in Behbahan in $2016-2017$. Medical Science 2018; 22(94):566-70.

12. Madmoli M, Modheji Y, Rafi A, Feyzi R, Darabiyan
P, AfsharNia A. Diabetes and its predictive role in the incidence of Alzheimer's disease. Medical Science 2019;23(95):30-4.

13. Madmoli M, Abbaszade Aliabad M, Madmoli M, Khodadadi M, Papi Ahmadi F. The Effect of Some Factors on Self-Care in Diabetic Patients: A Systematic Review. Journal of Genetics and Genetic Engineering. 2019;3(1):21-5.

14. Madmoli M. A Systematic Review Study on the Changer Factors of the Quality of life in Cancer Patients. Int. Res. Med. Health Sci., 2019; 2(1):8-15.

15. Madmoli M. A systematic Review Study on the Results of Empowerment-Based Interventions in Diabetic Patients. Int. Res. Med. Health Sci. 2019; 2(1):1-7.

16. Madmoli M, Shaidaei FMM, Rohani A, Darabiyan P, Mobarez F. The correlation between alcohol consumption and reducing the age of cancer incidence in patients with this disease. Medical Science. 2019:23(95):48-53.

17. Madmoli M, Mahmoudi Dehcheshmeh Z, Rafi A, Zahra Kord, Fariba Mobarez, Pouriya Darabiyan. The rate of some complications and risk factors of diabetes in diabetic patients: Study on cases of 3218 diabetic patients. Medical Science, 2019; 23(95):63-8. 18. Mostafa Madmoli, Mehran Yarbig, Negin Sedighi, Pouriya Darabiyan, Fariba Mobarez. Communication between body mass index and the risk of obesityrelated cancer: A 5-year study on patients with cancer. Medical Science, 2019; 23(95):69-74.

19. Madmoli M. Clinical and Laboratory Findingin Children with Leukemia: a Systematic Review. International Journal of Research Studies in Science, Engineering and Technology 2018;5(10):1-6.

20. Madmoli M. Evaluation of Chemotherapy Complications in Patients with Cancer: A systematic Review. International Journal of Research Studies in Science, Engineering and Technology 2018;5(12):5964.

21. Madmoli M, Madmoli Y, Khodadadi M, Samsamipour M. Study of Some Effective Treatments for Accelerating Diabetic Foot Ulcer Healing: A Systematic Review. International Journal of Research Studies in Science, Engineering and Technology. 2019;6(2):34-9.

22. Madmoli M, Madmoli $\mathrm{Y}$, Khodadadi $\mathrm{M}$, Samsamipour M. Factors Affecting the Level of Glycosylated Hemoglobin in Patients with Diabetes: A Systematic Review. Annals of Microbiology and Infectious Diseases 2019;2(1):43-7.

23. Madmoli M. A Systematic Review Study on the 
Communication between Diabetes and Cancer: The Serious Risk of Cancer in Diabetic Patients. International Research in Medical and Health Science. 2019;2(2):1-7.

24. Madmoli M. Quality of Life in Patients with Cancer and Some Factors Affecting it: A Systematic Review. International Journal of Research Studies in Science, Engineering and Technology 2019;6(1):1-7.

25. Madmoli M, Madmoli Y, Khodadadi M, Samsamipour M. Study of Some Effective Treatments for Accelerating Diabetic Foot Ulcer Healing: A Systematic Review. International Journal of Research Studies in Science, Engineering and Technology 2019;6(2):34-9.

26. Madmoli M, Madmoli Y, Khodadadi M, Samsamipour M. Factors Affecting the Level of Glycosylated Hemoglobin in Patients with Diabetes: A Systematic Review. Annals of Microbiology and Infectious Diseases 2019;2(1):43-7.

27. Madmoli M, Madmoli Y, Khodadadi M, Samsamipour M. Some Factors Affecting Quality of Life in Patients with Diabetes: A systematic Review", Annals of Microbiology and Infectious Diseases 2019;2(1):26-30.

28. Madmoli M, Saeidilandi M, Latifinasab R, Fatehimoghaddam SH, Mobarez F, Darabiyan P. Hypertension and Risk of Acute Coronary Syndrome (ACS) in Patients with ACS: A Study on 926 patients with ACS. International Journal of Ayurvedic Medicine. 2019;10(1).22-6.

29. Madmoli M, Shaidaei FBM, Rohani M, Madmoli M, Khodadadi M. Some predisposing factors and affecting cancer under the age of 35: A 6-year study on 2721 cancer patients. International Journal of Ayurvedic Medicine. 2019;10(1).62-7.

30. Madmoli M, Madmoli Y, Mobarez F, Taqvaeinasab $\mathrm{H}$, Darabiyan P, Rafi A. Drugs abuse and increase in referral to hospital to prevent Recurrence of diabetic foot ulcer infection. International Journal of Ayurvedic Medicine. 2019;10(1):89-94

31. Madmoli M, Madmoli Y, Taqvaeinasab H, Khodadadi M, Darabiyan P, Rafi A. Some influential factors on severity of diabetic foot ulcers and predisposing of limb amputation: A 7-year study on diabetic patients. International Journal of Ayurvedic Medicine. 2019;10(1):75-81.

32. Rafiee E, Khaledi M, Madmoli M, Zafari M, Lotfizadeh $M$. The correlation between Blood Pressure and BMI in Students of Shahrekord University of Medical Sciences in 2013-14. International Journal of Ayurvedic Medicine. 2019;10(1):113-7.

33. Madmoli Y, Madmoli M, Qashqaei NN,
Bosak S. Prevalence of depression and associated factors in adolescents of masjedsoleyman. JPEN. 2016; 2(4):31-40.

34. Madmoli M, Madmoli Y, Bigdeli Shamloo MB, Etebari A, Mahmoodi Kouhi A, Azami M. The Relationship Between Depression and Religiousness in Female High School Students of Masjed Soleyman in 2015. Journal of Pediatric Nursing. 2017;3(4):15-22. 35. Madmoli M, Nikpay S. An Investigation of the Relationship between Spiritual Health and Depression, Anxiety, and Stress among Students of Ilam University of Medical Sciences. Journal of Research in Medical and Dental Science. 2018;6(3):294-300.

36. Gheisari Z, Beiranvand R, Karimi A, Ghalavandi S, Soleymani A, Madmoli M, Bavarsad AH. Relationship between Occupational Stress and Cardiovascular Risk Factors Determination: A Case-control Study. Journal of Research in Medical and Dental Science. 2018 17;6(3):287-93.

37. Madmoli Y, Akhaghi Dezfuli SM, Adavi A, Maraaghi E, Heidari Soureshjani R, Madmoli M. The Effect of Orem Self-Care on Mental Health of Patients with Thalassemia Major. Journal of Clinical Nursing and Midwifery. 2018;7(2):108-15.

38. Madmoli M, Madmoli Y, Rahmati P, Adavi A, Yousefi N, Gheisari Z, Abbaszade Aliabad M. Quality of Life and Some Related Factors in Patients with Beta Thalassemia Major in Southwest Iran. Journal of Client-centered Nursing Care JCCNC. 2017;3(2):13946.

39. Madmoli Y, Beiranvand R, Korkini N, Mashalchi $\mathrm{H}$, Karimi H. Comparison of health related quality of life in beta thalassemia major and healthy people in Dezful in 2015. Iran J Nurs Res. 2016; 11(1):9-16.

40. Madmoli Y, Akhaghi Dezfuli SM, Beiranvand R, Saberi Pour B, Azami M, Madmoli M. An epidemiological and clinical survey of patients with $\beta$-thalassemia in dezful in 2015 (Persian). Iran J Epidemiol. 2017; 13(2):145-52.

41. Maraghi E, Adavi A, Madmoli Y, HeidariSoureshjani R, Madmoli M. The Effect of Orem SelfCare on Mental Health of Patients with Thalassemia Major. Journal of Clinical Nursing and Midwifery. 2018;4(3):108-15.

42. Madmoli M, Madmoli Y, Rahmati P, Adavi A, Yousefi N, Gheisari Z, Abbaszade Aliabad M. Quality of Life and Some Related Factors in Patients with Beta Thalassemia Major in Southwest Iran. Journal of Client-centered Nursing Care JCCNC. 2017;3(2):13946.

43. Madmoli Y, Akhaghi Dezfuli SM, Adavi A, Maraaghi E, Heidari Soureshjani R, Madmoli M. The 
Effect of Orem Self-Care on Mental Health of Patients with Thalassemia Major. Journal of Clinical Nursing and Midwifery. 2018 Jul 1;7(2):108-15.

44. Sona MF, Myung SK, Park K, Jargalsaikhan G. Type 1 diabetes mellitus and risk of cancer: a metaanalysis of observational studies. Japanese journal of clinical oncology. 2018 Apr 9;48(5):426-33.

45. Salehi F, Mohsenzade F, Arefi M. Prevalence of Death Anxiety in Patients with Breast Cancer in Kermanshah, Iranian Journal of Breast Diseases. 2016; 8 (4) :34-40

46. Khalili Z, Khatiban M, Faradmal J, Abbasi M, Zeraati F, Khazaei A. Effect of Cardamom aromas on the Chemotherapy-induced Nausea and Vomiting in Cancer Patients. Avicenna J Nurs Midwifery care. 2014;22(3):64-73.

47. Borhan F, Naji A, Molavi Vardanjnai M, Sasani L. Effects of Matricaria Chamomilla on the Severity of Nausea and Vomiting Due to Chemotherapy. Avicenna J Nurs Midwifery care. 2017;25(4):140-6.

48. Bosak S, Dashtbozorgi B, Hoseini M, Laifi M, Rezaei AR. The Effect of Massage Therapy on Nausea in Patients Who Undergo Chemotherapy for Breast Cancer. Jundishapur Journal of Chronic Disease Care. 2012;1(1):63-70.

49. Parsa-Yekta Z, Ebrahimi SM, Hosseini M, Nasrabadi AN, Sedighi S, Salehi-Surmaghi MH. Appeal of herbal plants as a mechanism for the relief of acute vomiting induced by chemotherapy. Razi Journal of Medical Sciences. 2012 Mar 15;18(93):33-9. 50. Sadat Hoseini AS. Effect of music therapy on chemotherapy nausea and vomiting in children with malignancy. Journal of hayat. 2009;15(2):5-14.
51. Najafi S. Ginger effects on control of chemotherapy induced nausea and vomiting. ijbd. 2014;7(1):7-14.

52. Sadeghi Shermeh M, Ebadi A, Sirati Nir M, Azadian M. Ice massage on chemotherapy induced nausea and vomiting. J Birjand Univ Med Sci. 2012;19 (1):1-11.

53. The Influence of Massage Therapy On Vomiting in Unde Chemothrapy Patient with Breast Cancer. ijbd. 2010; 3 (1 and 2):14-8.

54. Eghbali M, Varaei S, Jalalinia SF, Aalam Samimi M, Sa'atchi K, Yekaninejad MS. Effect of auricular acupressure on acute nausea and vomiting induced by chemotherapy among breast cancer patients. Journal of hayat. 2015;21(2):29-39.

55. Haddadi M, Ganjloo J, Hashemifard HR, Tabarraie Y. The Effect of Sucking Bits of Ice containing mint (mentha) Extract on Nausea and Vomiting Resulted of Chemotherapy in Patients Suffering from Malignant Cancer. Iranian Quarterly Journal of Breast Disease. 2017 Mar 15;9(4):7-14.

56. Warrier $\mathrm{P}$, Nambiar $\mathrm{V}$, Ramankutty C. Indian medicinal plants: A compendium of 500 species: Orient Blackswan; 1996.

57. Modares M, Besharat S, Mahmoudi M. Effect of Ginger and Chamomile capsules on nausea and vomiting in pregnancy. Journal of Gorgan University of Medical Sciences. 2012;14(1):46-51.

Source of support: Nil, Conflict of interest: None declared

Cite this article as:

Madmoli M, Samsamipour M. The Most Important Methods for Reducing Chemotherapy-Induced Nausea and Vomiting In Cancer Patients: A Systematic Review Study. Int Healthc Res J. 2019;3(1):3-8. doi: 10.26440/IHRJ/0301.04.521065

\section{AUTHOR AFFILIATIONS:}

1. Emergency Medical Technician, Dezful University of Medical Sciences, Dezful, Iran

2. Medical laboratory student, Student research Committee, Dezful University Medical Sciences, Dezful, Iran

*Corresponding Author: Mostafa Madmoli

Emergency Medical Technician

Dezful University of Medical Sciences Dezful, Iran 